Editorial

\title{
A New MDPI Proceedings Journal: Physical Sciences Forum
}

\section{Ioana Craciun}

Citation: Craciun, I. A New MDPI Proceedings Journal: Physical Sciences Forum. Phys. Sci. Forum 2021, 1, 1. https://doi.org/10.3390/ psf2021001001

Published: 25 June 2021

Publisher's Note: MDPI stays neutral with regard to jurisdictional claims in published maps and institutional affiliations.

Copyright: @ 2021 by the author. Licensee MDPI, Basel, Switzerland. This article is an open access article distributed under the terms and conditions of the Creative Commons Attribution (CC BY) license (http://creativecommons.org/licenses/by/4.0/).
MDPI AG, St. Alban-Anlage 66, 4052 Basel, Switzerland; ioana.craciun@mdpi.com

Conferences and scientific events are an important part of scientific communication and offer researchers, from both academia and industry, the opportunity to come together and build upon common research goals and ideas. At MDPI, we understand the importance of offering access to both of these meetings and materials, resulting from such scientific discussions to benefit the broad, worldwide, scientific community. Building upon this goal, we have launched Sciforum [1] and a series of proceedings journals [2] as platforms to support and organize conferences as well as communicate outcomes of conferences, webinars and other scientific events.

We are pleased to announce the expansion of our series of proceedings journals to include Physical Sciences Forum (ISSN 2673-9984) [3], a journal dedicated to proceedings on all aspects of physics, ranging from fundamental studies to emerging technologies. Physical Sciences Forum will publish primarily proceedings papers, extended abstracts and meeting reports related to scholarly events. Each conference proceeding can be individually indexed, is citable via a digital object identifier (DOI) and is freely available under an open access license, thus, increasing the visibility of the conference as well as the scientific content derived from the fruitful discussions.

We encourage conference or scientific event organizers to propose research outputs from their conferences to be published in Physical Sciences Forum and take advantage of our multiple benefits such as a dedicated webpage for your conference, no space constraints or color charges, attractive cover designs, Sciforum support and promotion of your conference on the MDPI journal websites, among others.

We look forward to collaborating with you and supporting your scientific community.

Conflicts of Interest: The author declares no conflict of interest.

\section{References}

1. Sciforum Home Page. Available online: https://sciforum.net/ (accessed on 9 June 2021).

2. MDPI Proceedings Journals Homepage. Available online: https://www.mdpi.com/about/proceedings (accessed on 9 June 2021).

3. Physical Sciences Forum Home Page. Available online: https://www.mdpi.com/journal/psf (accessed on 9 June 2021). 